\title{
Versicherung der Schweizer Ärzte Genossenschaft
}

RolfO. Heimgartner, Direktor

Korrespondenz:

Versicherung der Schweizer Ärzte Genossenschaft

Länggassstrasse 8

CH-3000 Bern 9

Tel. 0313012555

Fax 0313025156

versa@versa.ch

www.versa.ch

Am 17. Mai 2008 fand die 82. ordentliche Delegiertenversammlung der Versicherung der Schweizer Ärzte Genossenschaft, unter dem Präsidium von Herrn Dr. med. J. M. Fritzsche, im Hotel Les Trois Rois in Basel statt.

Anwesend waren 19 Delegierte sowie die Herren Dr. med. Otto P. Haab, Ehrenpräsident, Küssnacht; Peter W. Möschler, Versicherungsmathematiker, Bern; Richard Schaller, Versicherungsmathematiker/Aktuar, Weissensberg (D); Jakob Burkhard, stv. Direktor, sowie Armin Imoberdorf, Ernst \& Young AG, Bern; und Fritz Jakober, Vermögensverwalter, Glarus.

Die bis weit ins Berichtsjahr unter Volldampf laufende Wirtschaft sowie die stetig steigenden Rohstoffpreise führten zu einer deutlichen $\mathrm{Zu}$ nahme der Inflation. Die Notenbanken sahen sich deshalb veranlasst, durch Zinserhöhungen die Konjunkturentwicklung zu dämpfen, um weiteren Teuerungsrisiken entgegenzuwirken. So stiegen die kurz- und langfristigen Zinsen bis Mitte Jahr weltweit an. Die Aktienbörsen profitierten bis zu diesem Zeitpunkt von den munter sprudelnden Unternehmensgewinnen und lagen rund 10\% im Plus. Mit dem Ausbruch der US-Hypotheken- und -Immobilienkrise zog ein Gewitter über die Finanzmärkte herein, und die Anleger wurden risikoscheu. Viele spekulativ eingegangene Positionen wurden aufgelöst. Dies führte zu Umlagerungen in den sicheren Schweizer Franken und damit zu einer Aufwertung des zuvor schwachen Schweizer Frankens und zu teils massiven Abgaben an den Aktienmärkten, so dass die erzielten Gewinne bis Ende Jahr grösstenteils wieder preisgegeben werden mussten. Stark gesucht waren dafür die als sicher geltenden Staatsanleihen.

Das Platzen der Immobilienblase in den USA dürfte zu einer markanten Abkühlung der wirtschaftlichen Aktivitäten in Amerika führen, und auch die Weltwirtschaft wird davon nicht verschont bleiben. So steht den Finanzmärkten 2008 ein Jahr zwischen Hoffen und Bangen bevor.

Die Bilanzsumme beträgt im Berichtsjahr 2007 Fr. 1049841 000.-.
Die Kapitalanlagen teilen sich auf in:

\begin{tabular}{ll} 
Festverzinsliche Wertpapiere & Fr. 535902000 .- \\
\hline Aktien und Anlagefonds & Fr. 54069000 .- \\
\hline Anrechte Anlagestiftungen & Fr. 79790000 .- \\
Liegenschaften & Fr. 201501000 .- \\
Hypotheken & Fr. 108284000 .- \\
$\begin{array}{l}\text { Policendarlehen } \\
\text { Investitionskredite }\end{array}$ & Fr. 635000 .- \\
$\begin{array}{l}\text { Darlehensguthaben } \\
\text { (Festgelder und Callgelder) }\end{array}$ & Fr. 254000 .- \\
Derivate Finanzinstrumente & Fr. 5484000 .- \\
\hline
\end{tabular}

Die Delegiertenversammlung genehmigt einstimmig den Geschäftsbericht mit der Bilanz und der Betriebsrechnung für das Jahr 2007 und erteilt dem Verwaltungsratsausschuss, dem Verwaltungsrat und der Geschäftsleitung für das abgelaufene Geschäftsjahr Décharge.

Die Delegiertenversammlung folgt dem Antrag des Verwaltungsrates und beschliesst einstimmig, das nach Gutschrift und Äufnung der Rückstellungen verbleibende Jahresergebnis von Fr. 553 701.- wie folgt zu verwenden:

\begin{tabular}{ll} 
Zuweisung an die allgemeinen Reserven & Fr. $550000 .-$ \\
Zuweisung an den Hilfsfonds & Fr. $3701 .-$ \\
\cline { 2 - 2 } & Fr. $553701 .-$ \\
\hline
\end{tabular}

Für die nächste Amtsdauer als Verwaltungsrat, d.h. von der Delegiertenversammlung 2008 bis zur Delegiertenversammlung 2011, werden die folgenden Persönlichkeiten vorgeschlagen und einstimmig gewählt:

- Dr. med. Jürg M. Fritzsche, Präsident

- Dr. med. Balthasar Leuzinger

- Dr. med. Rolf Lehmann

- Prof. Dr. med. dent. Max O. Schmid

- Dr. med. vet. Pierre Berthold

- Dr. sc. math. Hanspeter Tobler

- Prof. Dr. rer. pol. Heinz Zimmermann

Für die Zeit von der Delegiertenversammlung 2008 bis zur Delegiertenversammlung 2009 wird die bisherige Revisionsstelle, Ernst \& Young AG, Bern, einstimmig gewählt. 